\title{
Erste CD byzantinisch-orthodoxer Musik in deutscher Sprache
}

\author{
Tillmann ReICHARDT ${ }^{*}$
}

Wer schon einmal die Liturgie in einer orthodoxen Kirche besucht hat, kennt die eindrucksvolle Atmosphäre, das Umfangen-sein von meditativen a-capella-Gesängen und die symbolträchtigen liturgischen Handlungen der Priester. Es ist ein fremdartiger, aber doch wohliger, inniger Eindruck für einen Christen aus der westlichen Welt, der auf den alten byzantinischen Ritus trifft. Leider gibt es bisher wenige Berührungspunkte zwischen beiden christlichen Traditionen. Darum ist eine Neuerscheinung bedeutsam: Zwischen den Osterfesten der West-und der Ostkirche erscheint die erste CD byzantinisch-orthodoxer Gesänge in deutscher Sprache - ein ökumenisches Projekt aus Rumänien.

Den meisten Christen in Deutschland, egal ob evangelisch oder katholisch, ist die Orthodoxe Kirche sehr fremd. Nicht wenige verbinden den Begriff „orthodox“ mit fundamentalistisch, starr, veraltet - etwas also, dass nicht mehr zeitgemäß ist und das es zu überwinden gilt. Erfahrungen mit der Orthodoxie als einer christlichen Konfession haben nur wenige, und einigen ist es nicht einmal bewusst, dass die Orthodoxe Kirche auch mit unserer westlichen christlichen Identität und Geschichte eng verwoben ist. Dabei blicken wir auf über 600 Jahre gemeinsame Geschichte zurück. Seit der Konstantinischen Wende im 4. Jh. nach Christus bis zum großen Schisma im Jahr 1054 gab es, trotz gelegentlicher Spannungen, eine gemeinsame christliche Kirche in Europa. Erst ab diesem Datum, spätestens jedoch seit der Eroberung Konstantinopels durch lateinische Kreuzfahrer im Jahr 1204, sprechen wir überhaupt von West- und Ostkirche als klar getrennten konfessionellen Einheiten, die sich vor allem im Westen im Laufe der Jahrhunderte und besonders im Zuge der Reformation noch in weitere Konfessionen aufspaltete. Dennoch beziehen wir uns in Deutschland, wenn wir von Ökumene sprechen, fast ausschließlich auf die verschiedenen Konfessionen der Westkirche, zumeist der evangelischen (lutherisch und reformiert) und der römisch-katholischen Kirche. Erst in den letzten Jahrzehnten hat sich der Blick auch der Protestanten stärker gen Osten gewandt. Die Bemühungen um gute gemeinsame ökumenische Beziehungen zwischen den drei großen christlichen Konfessionen in Europa haben stark zugenommen, und

\footnotetext{
* Tillmann Reichardt, Student der ev. Theologie an der Universität Leipzig. Adresse: AlbertSchweitzer-Str. 5, 04317 Leipzig, Deutschland; e-mail: tillmann.reichardt@yahoo.de.
}

RES 8 (1/2016), p. 154-156

DOI: $10.1515 /$ ress-2016-0012 
viele Vertreter der evangelischen wie auch der katholischen Kirche schauen in diesem Jahr gespannt auf das erste Pan-orthodoxe Konzil seit über 1000 Jahren in Kreta.

Zwischen die großen medienwirksamen Auftritte der kirchlicher Würdenträger in Ost und West im gemeinsamen Bemühen um einen ökumenischen Dialog mischt sich aber auch eine kleine, leisere Stimme aus einem mehrheitlich orthodox geprägten Land - Rumänien. In Hermannstadt (rum. Sibiu) ist das Institut für Ökumenische Forschung beheimatet. Seit vielen Jahren bemüht es sich schon nach Kräften um den Dialog zwischen evangelischer und orthodoxer Kirche. Hermannstadt mit seiner Multikonfessionalität bietet dafür einen fruchtbaren Nährboden.

Ein Meilenstein in der Arbeit des Instituts war die Einführung des neuen Ökumene-Semesters in deutscher Sprache, das hier seit vergangenem Jahr alljährlich angeboten wird und zum Ziel hat, deutschsprachige Theologiestudierende, aber auch bereits amtierende Pfarrer im ökumenischen Sinne weiterzubilden und damit den evangelisch-orthodoxen Dialog zu fördern. Eine erste Gruppe hat dieses Studienangebot bereits im vergangenen Jahr 2015 wahrgenommen. Sieben evangelische Studierende aus Deutschland und der Schweiz, sowie eine Teilnehmerin aus Hermannstadt konnten sich vier Monate lang intensiv mit der orthodoxen Theologie und Spiritualität auseinandersetzen und lernten auch etwas über die spezifische Situation und die interkonfessionellen Herausforderungen in Siebenbürgen. Das Lehrangebot, das mehrheitlich von orthodoxen Professoren getragen wurde, fand bei den Studierenden sehr großen Anklang.

Neben zahlreichen Exkursionen, in denen die Teilnehmer mit den verschiedenen Glaubensrichtungen in Siebenbürgen in Kontakt treten konnten und die Spiritualität der orthodoxen Klöster kennen lernten, besuchten sie auch einen Kurs zu byzantinischer Musik. Diese alte Form des Kirchengesangs in der Ostkirche hat seinen Ursprung, wie der Name schon suggeriert, in Byzanz und wurde in sogenannten „Neumen“ verschriftlicht - ein System, das sich stark vom westeuropäischen Notensystem unterscheidet. Vor allem in den orthodoxen Kirchen Südosteuropas wird diese Form des Gesanges verwendet, im Unterschied zu der russisch-orthodoxen Kirche. Deren Musik ist wesentlich stärker westlich beeinflusst und ähnelt eher der Gregorianik. Gemeinsam ist beiden Formen jedoch, dass sie vollständig auf Begleitung durch Instrumente verzichten. Das hat sowohl theologische als auch praktische Gründe. Ganz auf jegliche Form der Begleitung verzichtet die östliche Kirchenmusik aber dennoch nicht. Statt von Instrumenten wird die Melodiestimme von Sängern des Grundtons (griech. Ison) begleitet. Es ist eine sehr einfache Begleitung, durch 
die aber dennoch ein erstaunlicher Klangeffekt erreicht wird. Dadurch erhält die byzantinische Musik ihren getragenen, meditativen Charakter.

Diese Form des Gesangs also, die sich so stark von der westlichen Musik unterscheidet, erlernten auch die Teilnehmer des Ökumene-Semesters 2015. Am Ende dieser kleinen Musikausbildung stand die Aufnahme einer CD mit byzantinischer Musik in deutscher Übertragung. Insbesondere dem Dia.Logos-Verein, der eng mit dem Institut für Ökumenische Forschung Hermannstadt zusammenarbeitet, ist dieses Projekt ein wichtiges Anliegen. Bisher erklingen die Gesänge der orthodoxen Auslandsgemeinden in Deutschland zumeist in der Sprache des jeweiligen Ursprungslandes. Das möchte der Verein ändern, um auch den deutschsprachigen Gemeindegliedern den Zugang zur Kirchenmusik zu erleichtern. Ein weiteres Anliegen ist es aber auch, anderen musikalisch oder ostkirchlich interessierten Menschen diese Form des Gesangs näher zu bringen. Genau dieses Ziel soll nun mit der Veröffentlichung der ersten CD byzantinisch-orthodoxer Musik auf deutsch erreicht werden. In den Studios von Radio Trinitas in Hermannstadt trafen sich im Juli des vergangenen Jahres die evangelischen Studierenden mit orthodoxen Kantoren und ihrem Dozenten für byzantinische Musik, Diakon Alexandru Ioniță, und nahmen die erlernten Gesänge auf. Diese repräsentative Kollektion ostkirchlicher Klänge soll nun zwischen den beiden Osterfesten der West- und der Ostkirche erscheinen.

Für alle Interessierten sei dies eine gute Empfehlung sich die CD „Christus ist auferstanden - Byzantinische Gesänge aus dem Projekt Ökumene-Semester Hermannstadt" zu kaufen. Sie ist entweder für 6,- € (exkl. Versandkosten) über die Homepage des Dia.Logos-Vereins (dia-logos.ro) oder über den Schiller-Verlag (buechercafe.ro) beziehbar. Wer sich selbst einmal am byzantinischen Gesang versuchen möchte, findet die entsprechenden Partituren online und kostenlos zum Download, ebenfalls auf der Homepage des Vereins. Sie sind sowohl in Neumen als auch in westeuropäischer Notation verschriftlicht.

Wer sich dagegen etwas mehr mit orthodoxer Theologie und Spiritualität beschäftigen und nebenbei orthodoxe Gesänge erlernen möchte, dem sei das Studiensemester in Hermannstadt ans Herz gelegt. Falls Sie selbst Theologie studieren oder studiert haben, ist dies eine wunderbare Gelegenheit, Ihr Wissen in Bezug auf die Tradition des Ostens zu erweitern und einen Einblick in die Geschichte und die Situation der evangelischen Kirche A.B. in Rumänien zu bekommen. Nähere Informationen dazu finden Sie auf der Internetseite des Instituts für Ökumenische Forschung (ecum.ro). 